\title{
COMPARAÇÃO DE METODOLOGIAS PARA A DETERMINAÇÃO DE UMIDADE EM GELÉIA REAL
}

\author{
Luis Henrique Garcia-Amoedo e Ligia Bicudo de Almeida-Muradian*
}

Faculdade de Ciências Farmacêuticas, Universidade de São Paulo, Av. Prof. Lineu Prestes, 580, bloco 14, 05508-900 São Paulo - SP

Recebido em 11/6/01; aceito em 21/11/01

\begin{abstract}
COMPARISON OF METHODOLOGIES FOR ROYAL JELLY'S MOISTURE DETERMINATION. The aim of this paper was to compare methods of moisture determination to choose the best one for the determination of this parameter in royal jelly samples. Royal jelly is sensitive to high temperatures becoming dark and loosing volatiles in high temperatures. The methods were: vacuum oven at $60^{\circ} \mathrm{C}, 70^{\circ} \mathrm{C}$, conventional oven at $105{ }^{\circ} \mathrm{C}$, Karl Fisher, dissecator with sulfuric acid and dryness with infrared light at $105^{\circ} \mathrm{C}$. Based on the results, the best method was the dissecator with sulfuric acid for moisture determination in royal jelly.
\end{abstract}

Keywords: royal jelly; moisture; methods.

\section{INTRODUÇÃO}

A geléia real é uma substância viscosa, de coloração brancoamarelada, ou branco-acinzentada, levemente opalescente, de odor característico e pungente, porém não desagradável ou rançoso ${ }^{1}$. Sua composição química foi determinada como sendo $63 \%$ de umidade, $1 \%$ de cinzas, 3,5\% de lipídios, $13 \%$ de proteínas e 19,5\% de carboidratos ${ }^{1}$.

Ela é secretada pelas glândulas mandibulares hipofaríngeas das abelhas operárias jovens. É um dos produtos mais importantes para a colméia, pois serve de alimento para as larvas em desenvolvimento, e para a abelha rainha por toda a sua vida.

Por ser um produto de difícil obtenção (geralmente em quantidades pequenas) e de grande procura, por conta dos benefícios que são atribuídos ao seu uso, tais como aumento de fertilidade ${ }^{2}$, atividade antileucêmica e contra tumores ascíticos ${ }^{3}$, atividade antibiótica ${ }^{4}$, e hipocolesterolemiante ${ }^{5}$, alcança preço considerável no comércio, sendo mesmo comuns os episódios de adulteração do mesmo, por adição de substâncias com o intuito de aumentar-lhe o volume. Um dos adulterantes mais comumente utilizados é a água ${ }^{1}$.

Howe et al. em $1985^{6}$ analisaram amostras de geléia real obtidas do comércio contra amostras frescas, considerando estas últimas como padrão de qualidade, para a determinação da composição centesimal. Foram determinados os teores de umidade, proteínas totais, lipídios totais, a composição dos aminoácidos e dos ácidos graxos. A caracterização e composição da geléia real também foram objeto de estudo de Karaali et al. ${ }^{7}$ que estudaram a geléia real turca e determinaram umidade, açúcares totais, lipídios, proteínas, aminoácidos, cinzas, minerais (ferro e cálcio) e vitaminas (tiamina, riboflavina e niacina).

Em 1992, Palma $^{8}$, baseando-se no fato de não haver um padrão estabelecido que pudesse ser usado pelas agências regulatórias no Brasil para controlar a adulteração nos produtos comerciais derivados de geléia real, iniciou um estudo para determinar a composição química da geléia real de procedência brasileira. Analisou a umidade, proteínas, cinzas, lipídios, açúcares e acidez. O pesquisador verificou que sua composição é concordante com os valores descritos por outros autores, embora algumas diferenças possam ser indicadas, tais como o fato de as amostras brasileiras serem levemente mais

\footnotetext{
*e-mail: ligiabi@usp.br
}

úmidas que os exemplos citados na literatura. Na legislação brasileira recentemente publicada $\left(\right.$ Brasil $\left.^{9}, 2001\right)$ a faixa de umidade permitida para a geléia real fresca é de 60 a 70\%, no entanto não é mencionada qual a metodologia que deve ser utilizada para tal análise. O objetivo deste trabalho foi comparar diferentes metodologias para a determinação de umidade em geléia real.

\section{PARTE EXPERIMENTAL}

\section{Material}

Cada uma das amostras de geléia real (total de 7 amostras, que foram analisadas em triplicata cada uma) foi adquirida em um dos apiários ou entrepostos de comercialização de produtos apícolas filiados à ABRACAM (Associação Brasileira de Apicultores Criadores de Abelhas Mansas) ou à APACAME (Associação Paulista de Apicultores Criadores de Abelhas Melíferas Européias), ou ainda de outros apicultores produtores de geléia real no Estado de São Paulo.

Todas as amostras foram mantidas sob refrigeração a $-18^{\circ} \mathrm{C}$ e ao abrigo da luz, desde o recebimento até o momento da análise. Cada amostra de geléia real foi proveniente de um apicultor fornecedor, e correspondente a um lote de produção apícola. As amostras, foram marcadas com letras, que serviram para identificá-las nas citações, sendo: A, B, C, D, E, F e G

\section{Métodos}

\section{Determinação da umidade}

A determinação da umidade na geléia real foi realizada por métodos gravimétricos convencionais e por método volumétrico.

Os métodos gravimétricos empregados tomaram por base a perda de massa da amostra, por dessecação até peso constante:

- em estufa à vácuo regulada para $60^{\circ} \mathrm{C}^{10,11}$ (Fanem, Brasil)

- em estufa à vácuo regulada para $70^{\circ} \mathrm{C}^{10,11}$ (Fanem, Brasil)

- em estufa convencional regulada para $105^{\circ} \mathrm{C}^{10,11}$ (Fanem, Brasil)

- em ambiente de baixa atividade de água ${ }^{10}$, utilizando-se dessecador com ácido sulfúrico, e

- por secagem sob infravermelho ${ }^{10}$, em equipamento "Unidade de secagem Mettler LTJ" (Mettler, Brasil) ajustando-se a intensidade da radiação emitida de modo que a amostra atingisse $105^{\circ} \mathrm{C}$. 
Em todos os casos, uma alíquota de cada uma das amostras (analiticamente cerca de $1 \mathrm{~g}$ ) foi submetida ao processo, até peso constante, e o teor de umidade foi calculado utilizando-se a equação (1):

$\%$ umidade $=100-\left(\left(\left(m^{\prime}-t\right) /(m-t)\right) \times 100\right)$

onde:

$\mathrm{m}=$ massa total do sistema (vidraria mais alíquota da amostra) no início do processo

m' = massa total do sistema (vidraria mais alíquota da amostra) no final do processo

$\mathrm{t}=$ massa da vidraria utilizada

$100=$ fator percentual de cálculo

Para a determinação de umidade por submissão da amostra a ambiente com baixa atividade de água, uma alíquota da amostra de cerca de $1 \mathrm{~g}$ foi tomada em vidro de relógio e imediatamente posta em um dessecador com ácido sulfúrico, nele permanecendo por $15 \mathrm{~h}$.

O equipamento para determinação de umidade por utilização de radiação infravermelho é composto por uma balança que possui acoplada uma fonte da radiação. Para a realização da análise, uma alíquota da amostra foi aplicada a um suporte previamente tarado (na maioria dos casos este suporte é um pequeno prato de alumínio). O conjunto suporte mais alíquota da amostra foi colocado na balança, e a massa inicial foi registrada. Em seguida fez-se incidir a radiação sobre a amostra, e a massa final (peso constante) após o processo foi novamente registrada.

A determinação de umidade pelo método volumétrico, baseouse na aquametria com reagente de "Karl Fischer" 10,11.

$\mathrm{O}$ teor de umidade foi estimado tomando-se por base a quantidade de reagente (com seu respectivo fator de correção) necessária para titular a água presente na alíquota da amostra ensaiada. O cálculo foi feito utilizando a equação (2):

$\%$ umidade $=((\mathrm{v} \times \mathrm{fc}) / \mathrm{AAE}) \times 100$

onde:

$\mathrm{v}=$ volume de reagente de "Karl Fischer" gasto para titular a água presente na alíquota de amostra ensaiada

$\mathrm{fc}=$ fator de correção do equivalente em água capaz de ser neutralizado pelo reagente de "Karl Fischer"

AAE = alíquota de amostra ensaiada

100 = fator percentual de cálculo

\section{Análise estatística}

Foi realizada a análise de variância para a comparação dos diversos métodos de determinação da porcentagem de umidade da geléia real, utilizando-se um efeito bloco para controle da variação implícita de cada amostra.

Devido ao fato de que os métodos não forneceram resultados semelhantes (médias iguais), utilizou-se a análise de contraste ${ }^{12}$.

\section{RESULTADOS E DISCUSSÃO}

Dentre os itens mais freqüentemente analisados em alimentos, o teor de umidade é um importante dado de composição, e em alguns casos é também um indicador da qualidade do produto.

Sua determinação é normalmente feita por métodos gravimétricos, também conhecidos como dessecação até peso constante; estes métodos são indiretos, e determinam a umidade através da diferença de massa entre o alimento úmido e o seco.

De acordo com as "Normas Analíticas do Instituto Adolfo Lutz"10, o aquecimento direto da amostra à $105^{\circ} \mathrm{C}$ é o processo mais utiliza- do para a análise de alimentos em geral. Assim sendo, foi realizada a determinação do teor de umidade das amostras de geléia real, primeiramente, em estufa convencional cuja temperatura foi regulada para $105^{\circ} \mathrm{C}$.

Sob estas condições de processo, os resultados obtidos foram que as amostras apresentaram aspecto vítreo e coloração castanhoescuro ao final do processo, os quais são característicos de reações de escurecimento. Originalmente, a geléia real, que apresenta coloração amarelo-claro e aspecto cremoso, é muito diferente do produto obtido após a secagem a $105^{\circ} \mathrm{C}$.

As amostras tiveram uma perda de massa média de $69 \%$, variando entre 64,07 e 71,94\%.

Quando as amostras se decompõem ou iniciam transformações a $105^{\circ} \mathrm{C}$ (como ocorreu com as amostras de geléia real), o teor de umidade deve ser obtido por processo semelhante, porém em estufa à vácuo com temperatura regulada para $70^{\circ} \mathrm{C}^{10}$.

Os resultados obtidos sob essas condições também não foram satisfatórios. As amostras continuaram apresentando modificações na cor. Em $70{ }^{\circ} \mathrm{C}$, as amostras tiveram uma perda de massa média de $67,57 \%$, variando entre $62,38 \%$ e $70,83 \%$.

Buscando ainda resolver a questão do escurecimento que se forma durante a análise, as amostras foram então submetidas ao processo em estufa a vácuo regulada para $60^{\circ} \mathrm{C}$.

De forma idêntica ao ocorrido anteriormente, as amostras submetidas a $60{ }^{\circ} \mathrm{C}$ a vácuo também apresentaram alterações na cor.

Ao comparar os resultados obtidos nos processos a $60{ }^{\circ} \mathrm{C}$, a $70{ }^{\circ} \mathrm{C}$ e a $105^{\circ} \mathrm{C}$, pôde-se notar em todas as amostras, uma alteração visível da cor ocasionada, provavelmente, por reações de escurecimento não enzimático ( Reação de "Maillard") e de caramelização formando HMF (hidroximetilfurfural) ${ }^{13}$. As amostras submetidas à $105^{\circ} \mathrm{C}$ eram nitidamente mais escuras que as amostras submetidas à $70^{\circ} \mathrm{C}$, e estas, mais escuras que as submetidas à $60^{\circ} \mathrm{C}$.

Os açúcares e aminoácidos livres que existem naturalmente na geléia real ${ }^{14-16}$, podem ser apontados como os possíveis responsáveis pelo escurecimento não enzimático. Os estudos realizados por Chen e Chen ${ }^{17}$, demonstraram que durante o armazenamento de geléia real em condições ambientes, já é possível notar escurecimento, devido à reação de "Maillard".

A partir destes resultados, experimentou-se um método alternativo, que foi a determinação de umidade sob radiação infravermelha. Este método, embora exponha as amostras a um aumento de temperatura, o faz por períodos curtos, fato este, que poderia contribuir para a preservação da integridade das mesmas.

$\mathrm{Na}$ determinação de umidade por exposição a radiação infravermelha, o teor médio obtido foi de $63,74 \%$, variando entre 59,89 e $66,04 \%$.

Ao final do processo, as amostras apresentavam-se claras e endurecidas, com aspecto resinoso, e com o odor característico da geléia real, porém mais acentuado.

Foram ainda utilizados métodos que não empregam o calor. As amostras foram submetidas a um ambiente com baixa atividade de água (dessecador com ácido sulfúrico), e também à aquametria por titulação com reagente de "Karl Fischer".

A aquametria por titulação com reagente de "Karl Fischer" revelou resultado médio de umidade de $65,77 \%$, entre um mínimo de $60,92 \%$ e um máximo de $67,82 \%$. Os valores obtidos no presente estudo são próximos aos descritos por Serra-Bonvehi ${ }^{15}(66,40 \%)$ na análise de amostras de origem chinesa.

Durante a realização destas análises, foi possível notar que ao adicionar a amostra ao frasco de titulação, assim que ela entra em contato com o metanol anidro, forma-se em sua superfície uma película endurecida e de cor branca. Tal fato, leva a crer que o endurecimento produzido, possivelmente por denaturação protéica, aprisio- 
na o conteúdo de seu interior, tornando as trocas com o ambiente mais lentas, o que torna o tempo necessário para a titulação maior (cerca de $20 \mathrm{~min}$ ).

No processo em dessecador com ácido sulfúrico, as amostras apresentaram um aspecto final semelhante àquele descrito quando da análise por radiação infravermelho: coloração clara, consistência endurecida, como se formasse um filme plástico. Neste caso, as amostras tiveram uma perda de massa média de $63,24 \%$, variando entre 61,45 e $67,58 \%$.

Na Figura 1 são apresentados os valores médios de umidade de todas as amostras, em relação aos métodos utilizados.

É possível notar que de modo geral, nos processos nos quais o calor é empregado, os valores de umidade são maiores que nos outros processos; exceção deve ser feita à exposição da amostra à radiação infravermelho, onde há aplicação de calor, porém por um curto período de tempo. Há ainda que ressaltar, que nos processos que envolvem o calor, outros componentes voláteis das amostras podem ser perdidos nas condições de análise. Os ácidos graxos de cadeia curta, naturalmente presentes na geléia real ${ }^{18}$, compostos voláteis e água provenientes de reação de escurecimento não enzimático, podem ser exemplos dessas perdas durante a realização das análises.

Palma ${ }^{8}$ ao analisar amostras brasileiras de geléia real, por aquecimento a $65{ }^{\circ} \mathrm{C}$, encontrou valor médio de umidade entre 67,8 e $69,4 \%$.

Foi realizada a análise de variância das médias dos teores de umidade obtidos através dos distintos processos, e concluiu-se que em nível de significância de 5\% estas são estatisticamente diferentes. A análise de variância está apresentada na Tabela 1.

Nem todos os processos resultam no mesmo valor de umidade. Através do método de contraste pode-se obter quais destes resultam valores não diferentes estatísticamente. Vide Tabela 2.

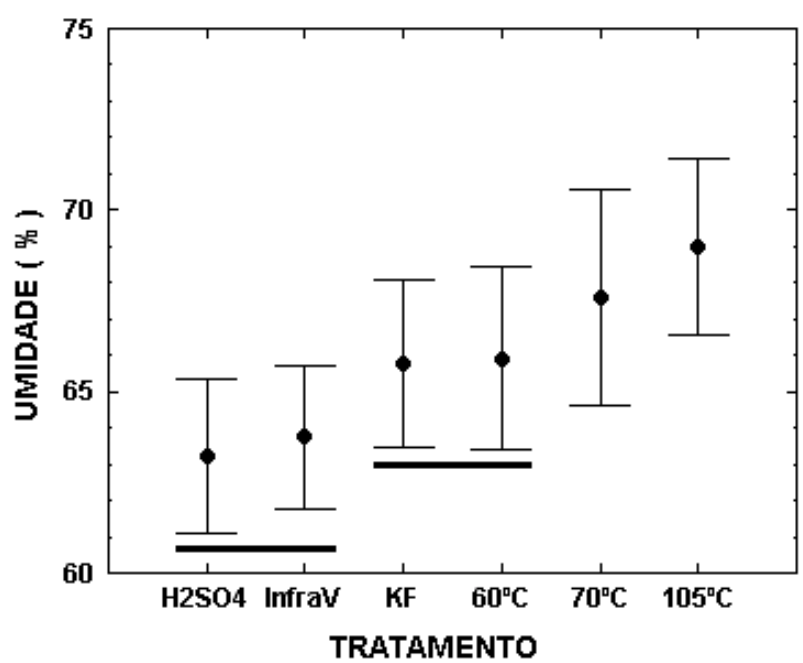

Figura 1. Valores médios de umidade encontrados em amostras de geléia real; comparação entre processos

$60^{\circ} \mathrm{C}=$ Determinação de umidade em estufa à vácuo regulada para $60^{\circ} \mathrm{C}$

$70{ }^{\circ} \mathrm{C}=$ Determinação de umidade em estufa à vácuo regulada para $70^{\circ} \mathrm{C}$

$105^{\circ} \mathrm{C}=$ Determinação de umidade em estufa regulada para $105{ }^{\circ} \mathrm{C}$

$I V=$ Determinação de umidade por exposição da amostra à radiação infravermelha

$\mathrm{H}_{2} \mathrm{SO}_{4}=$ Determinação de umidade por exposição da amostra a ambiente de baixa atividade de água (dessecador de ácido sulfúrico)

$K F=$ Aquametria por titulação com reagente de "Karl Fischer"

工 Média \pm Desvio Padrão

- Média

- Médias iguais estatisticamente (ao nível de 5\%)

Tabela 1. Análise de Variância dos efeitos dos diversos métodos de análise de obtenção de porcentagem de umidade em amostras de geléia real obtidas no Estado de São Paulo

\begin{tabular}{lccccc}
\hline FONTE & GRAUS DE & SOMA DOS & QUADRADO \\
LIBERDADE & QUADRADOS & MÉDIO & F & PÍSTICA & P-valor** CONCLUSÃO * \\
& & & & \\
\hline
\end{tabular}

\begin{tabular}{lllllll}
\hline Efeito do Tratamento & 5 & 507,1 & 101,42 & 62,28 & 0,000 & rejeita H0
\end{tabular}

estufa $105{ }^{\circ} \mathrm{C} 69,00(2,44)$

estufa vácuo $70^{\circ} \mathrm{C} 67,57(2,97)$

estufa vácuo $60{ }^{\circ} \mathrm{C} 65,91(2,52)$

Karl Fischer 65,77 $(2,29)$

Rad.Infravermelha 63,74 $(1,97)$

$\mathrm{H}_{2} \mathrm{SO}_{4} 63,24(2,12)$

Efeito da Amostra (Bloco)

Resíduo ( Erro )

Total

6

144

125
509,3

185,6

1202,1
$84,88 \quad 52,13 \quad 0,000$

rejeita $\mathrm{H} 0$

* - conclusão ao nível de significância de 5\% ; **P-valor - nível descritivo ; dp - desvio padrão

MODELO

$\mathrm{UMIDADE}=\mu+$ tratamento + bloco $+\varepsilon$

HIPÓTESES DO TESTE

Ho : todas as médias são iguais

HA: pelo menos uma média é diferente

ESTATÍSTICA DO TESTE

FOBS > FCRITICO (ou equivalente se o nível descritivo for menor que 0,050) rejeita a hipótese H0, ou seja, pelo menos uma média difere e portanto existe efeito da fonte de variação 
Tabela 2: Análises de contrastes (Método de Dunkan) entre os diversos métodos de umidade para amostras de geléia real do Estado de São Paulo.

\begin{tabular}{|c|c|c|c|c|}
\hline \multicolumn{3}{|c|}{ diferenças entre médias } & \multirow{2}{*}{$\begin{array}{c}\text { d. } \mathbf{m} . \mathbf{s} * * \\
0,884\end{array}$} & \multirow{2}{*}{$\begin{array}{c}\begin{array}{c}\text { conclusão a 5\% } \\
\text { de significância }\end{array} \\
\text { rejeita H0 }\end{array}$} \\
\hline 105 & $-\mathrm{H}_{2} \mathrm{SO}_{4}$ & $=5,76$ & & \\
\hline 105 & - IV & $=5,26$ & 0,868 & rejeita $\mathbf{H 0}$ \\
\hline 70 & $-\mathrm{H}_{2} \mathrm{SO}_{4}$ & $=4,33$ & 0,868 & rejeita $\mathbf{H 0}$ \\
\hline 105 & $-\mathrm{KF}$ & $=3,24$ & 0,849 & rejeita $\mathbf{H 0}$ \\
\hline 70 & - IV & $=3,83$ & 0,849 & rejeita $\mathbf{H 0}$ \\
\hline 60 & $-\mathrm{H}_{2} \mathrm{SO}_{4}$ & $=2,67$ & 0,849 & rejeita $\mathbf{H 0}$ \\
\hline 105 & -60 & $=3,09$ & 0,821 & rejeita $\mathbf{H 0}$ \\
\hline 70 & $-\mathrm{KF}$ & $=1,81$ & 0,821 & rejeita $\mathbf{H O}$ \\
\hline 60 & - IV & $=2,17$ & 0,821 & rejeita $\mathbf{H 0}$ \\
\hline $\mathrm{KF}$ & $-\mathrm{H}_{2} \mathrm{SO}_{4}$ & $=2,52$ & 0,821 & rejeita $\mathbf{H O}$ \\
\hline 105 & -70 & $=1,43$ & 0,780 & rejeita $\mathbf{H 0}$ \\
\hline 70 & -60 & $=1,66$ & 0,780 & rejeita $\mathbf{H 0}$ \\
\hline 60 & $-\mathrm{KF}$ & $=0,15$ & 0,780 & aceita H0 \\
\hline $\mathrm{KF}$ & - IV & $=2,02$ & 0,780 & rejeita $\mathbf{H 0}$ \\
\hline IV & $-\mathrm{H}_{2} \mathrm{SO}_{4}$ & $=0,50$ & 0,780 & aceita $\mathrm{HO}$ \\
\hline
\end{tabular}

\section{CONCLUSÃO GERAL*}

$\frac{\mathrm{H}_{2} \mathrm{SO}_{4} \quad \mathrm{IV}}{*} \frac{\mathrm{KF}}{*}-$ médias estatisticamente iguais ao nível de $5 \%$ de
significância

** d. m. s.- diferença média significativa ao nível de 5\%

\section{HIPÓTESES DO TESTE}

Ho : as medias A e B são iguais (ao nível de 5\%)

HA: as medias A e B não são iguais (ao nível de 5\%)

\section{ESTATÍSTICA DO TESTE}

média A - média B > d. m. s. rejeita $\mathrm{HO}$, ou seja, as médias A e B não são iguais ao nível de significância de 5\%

Através desta análise pode-se notar que em nível de significância de $5 \%$, possuem médias não diferentes estatisticamente os seguintes tratamentos:

- Aquametria por titulação com reagente de Karl Fischer e gravimetria após aquecimento em estufa a vácuo regulada para $60{ }^{\circ} \mathrm{C}$.

- Gravimetria em aparelho para determinação de umidade por exposição da amostra à radiação infravermelho e exposição da amostra a ambiente de baixa atividade de água (dessecador de ácido sulfúrico).

Conforme a indicação da análise estatística, o método que emprega ambiente de baixa atividade de água (dessecador de ácido sul- fúrico) se equivale ao método que utiliza Infra vermelho, tendo obtido os menores valores de umidade, comparando-se aos outros métodos.

No caso do método que que emprega ambiente de baixa atividade de água (dessecador de ácido sulfúrico), este tem a vantagem de que sua execução não exige aparelhagem sofisticada e tem baixo custo relativo, podendo ser indicado para a rotina do controle da qualidade do produto, mesmo em laboratórios menos equipados e favorecidos.

Quanto ao método que utiliza infravermelho, este tem a vantagem de ser mais rápido e poderia ser mais vantajoso para as análises de controle de qualidade de um laboratório mais equipado onde o número de amostras geralmente é muito grande.

Como só foi possível a obtenção de sete amostras de produtores do Estado de São Paulo, considera-se uma amostragem pequena, portanto os dados obtidos neste trabalho são mais indicativos do que conclusivos, sugerindo-se uma continuação deste com maior número de amostras.

\section{AGRADECIMENTO}

L. B. de Almeida-Muradian agradece a Bolsa de Produtividade em Pesquisa recebida do CNPq.

\section{REFERÊNCIAS}

1. Garcia-Amoedo, L. H.; Dissertação de Mestrado, Universidade de São Paulo, Brasil, 1999.

2. Evans, H. M.; Emerson, G. A.; Eckert, J. E.; J. Econ. Entomol. 1937, 30, 642.

3. Townsend, G.F.; Morgan, J. F., Hazlett, B.; Nature 1959, 183, 1270.

4. Blum, M. S.; Novak, A. F.; Taber, S.; Science 1959,130, 452.

5. Cho, Y. T.; Am. Bee J. 1977, 117, 36.

6. Howe, S. R.; Dimick, P. S.; Benton, A. W.; J. Apic. Res. 1985. 24, 52.

7. Karaali, A.; Meydanoglu, F.; Eke, D.; J. Apic. Res. 1988. 27, 182.

8. Palma, M. S.; J. Apic. Res. 1992. 31, 42.

9. http://www.agricultura.gov.br/sda/dipoa/instrução_normativa03_01.htm, acessada em Outubro 2001.

10. Instituto Adolfo Lutz; Normas analíticas do Instituto Adolfo Lutz, São Paulo, 1985, p. 21.

11. Comissão Permanente de Revisão da Farmacopéia Brasileira; Farmacopéia Brasileira, Atheneu: São Paulo, 1988, v. 4.2.3.

12. Costa Neto, P. L. O.; Estatística, São Paulo, 1977.

13. Berk, Z. Em Braverman's Introduction to the Biochemistry of Foods; Amsterdam, 1976.

14. Lercker, G.; Capella, P.; Conte, L.S.; Ruini, F.; Giordani, G.; Lipids 1981, 16, 912

15. Serra-Bonvehí, J.; An. Bromatol. 1992, 44, 65.

16. Serra-Bonvehí, J.; An. Bromatol. 1990, 42, 353

17. Chen, C.; Chen, S. Y.; Food Chem. 1995, 54, 195.

18. Weaver, N.; Johnston, N. C.; Benjamin, R.; Law, J. H.; Lipids 1969, 3, 535. 